\title{
Climate response to the Samalas volcanic eruption in 1257 revealed by proxy records
}

Article

Accepted Version

Guillet, S., Corona, C., Stoffel, M., Khodri, M., Lavigne, F., Ortega, P., Eckert, N., Sielenou, P. D., Daux, V., Churakova (Sidorova), O. V., Davi, N., Edouard, J.-L., Zhang, Y., Luckman, B. H., Myglan, V. S., Guiot, J., Beniston, M., Masson-Delmotte, V. and Oppenheimer, C. (2017) Climate response to the Samalas volcanic eruption in 1257 revealed by proxy records. Nature Geoscience, 10 (2). pp. 123-128. ISSN 1752-0894 doi: https://doi.org/10.1038/ngeo2875 Available at https://centaur.reading.ac.uk/68817/

It is advisable to refer to the publisher's version if you intend to cite from the work. See Guidance on citing.

Published version at: http://dx.doi.org/10.1038/ngeo2875

To link to this article DOI: http://dx.doi.org/10.1038/ngeo2875

Publisher: Nature Publishing Group

All outputs in CentAUR are protected by Intellectual Property Rights law, including copyright law. Copyright and IPR is retained by the creators or other copyright holders. Terms and conditions for use of this material are defined in the End User Agreement. 


\section{CentAUR}

Central Archive at the University of Reading

Reading's research outputs online 


\section{Climate response to the 1257 Samalas eruption revealed by proxy records}

Sébastien Guillet ${ }^{1, *}$, Christophe Corona ${ }^{2}$, Markus Stoffel ${ }^{1,3,4, *}$, Myriam Khodri ${ }^{5}$, Franck Lavigne ${ }^{6}$, Pablo Ortega ${ }^{7}$, Nicolas Eckert ${ }^{8}$, Pascal Dkengne Sielenou ${ }^{8}$, Valérie Daux ${ }^{9}$, Olga V. Churakova (Sidorova $^{1,10}$, Nicole Davi ${ }^{11,12}$ Jean-Louis Edouard ${ }^{13}$, Yong Zhang ${ }^{14,15}$, Brian H. Luckman ${ }^{16}$, Vladimir S. Myglan ${ }^{17}$, Joël Guiot ${ }^{18}$, Martin Beniston ${ }^{3}$, Valérie Masson-Delmotte ${ }^{9}$ \& Clive Oppenheimer ${ }^{19}$

${ }^{1}$ Dendrolab.ch, Institute of Geological Sciences, University of Berne, Baltzerstrasse 1+3, CH-3012 Berne, Switzerland.

${ }^{2}$ Geolab, UMR 6042 CNRS, Université Blaise Pascal, 4 rue Ledru, F-63057 Clermont-Ferrand, France.

${ }^{3}$ Climatic Change and Climate Impacts, Institute for Environmental Sciences, University of Geneva, 66 Boulevard Carl Vogt, CH-1205 Geneva, Switzerland.

${ }^{4}$ Department of Earth Sciences, University of Geneva, rue des Maraîchers 13, CH-1205 Geneva, Switzerland.

${ }^{5}$ Laboratoire d'Océanographie et du Climat: Expérimentations et approches numériques, Université Pierre et Marie Curie, 4 place Jussieu, F-75252 Paris Cedex 05, France.

${ }^{6}$ Laboratoire de Géographie Physique, Université Paris 1 Panthéon-Sorbonne, 1 place Aristide Briand, 92195 Meudon, France.

${ }^{7}$ NCAS-Climate, Department of Meteorology, University of Reading, Reading RG66BB, United Kingdom.

${ }^{8}$ Irstea, UR ETNA / Université Grenoble-Alpes, 2 rue de la Papeterie, F-38402 Saint Martin d'Hères, France.

${ }^{9}$ Laboratoire des Sciences du Climat et de l'Environnement (CEA-CNRS-UVSQ UMR8212, Institut Pierre Simon Laplace, Université Paris Saclay), L'Orme des Merisiers, F-91191 Gif-sur-Yvette, France

${ }^{10}$ V.N. Sukachev Institute of Forest, 660036 Krasnoyarsk, Akademgorodok, Russian Federation

${ }^{11}$ Department of Environmental Science, William Paterson University, Wayne, NJ, 07470, USA.

${ }^{12}$ Lamont Doherty Earth Observatory of Columbia University, University of Arizona, Palisades, NY 10964, USA

${ }^{13}$ CCJ, UMR 7299 CNRS, Maison méditerranéenne des Sciences de l'homme 5 rue du château de l'horloge, 13094 Aix-en-Provence cedex, France

${ }^{14}$ Key Laboratory of Land Surface Pattern and Simulation, Institute of Geographic Sciences and Natural Resources, Chinese Academy of Sciences, Beijing 100101, China.

${ }^{15}$ Center for Excellence \& Innovation in Tibetan Plateau Earth System Sciences, Chinese Academy of Sciences, Beijing 100101, China.

${ }^{16}$ Department of Geography, University of Western Ontario, 1151 Richmond Street, London, Ontario, Canada, N6A 5C2, Canada.

${ }^{17}$ Siberian Federal University, RU-660041 Krasnoyarsk, Russia

${ }^{18}$ CEREGE, CNRS and Aix-Marseille University, Europole Mediterraneen de l'Arbois, F-13545 Aix-en-Provence, France.

${ }^{19}$ Department of Geography, University of Cambridge, Downing Place, Cambridge CB2 3EN, United Kingdom

* Corresponding authors: sebastien.guillet@dendrolab.ch, markus.stoffel@dendrolab.ch

The eruption of Samalas in Indonesia in 1257 ranks among the largest sulfur-rich eruptions of the Common Era with sulfur deposition in ice cores reaching twice the volume of the Tambora eruption in 1815. Sedimentological analyses of deposits confirm the exceptional magnitude $\left(M_{e} 7\right.$, VEI 7) of the Samalas eruption with $\geq 40 \mathrm{~km}^{3}$ of dense magma expelled and a plinian column estimated to reach $43 \mathrm{~km}$. However, the climatic response to the Samalas event is debated since climate model simulations generally predict a stronger and more prolonged surface air cooling of Northern Hemisphere (NH) summers than inferred from tree-ring based temperature reconstructions. Here, we draw on historical archives, ice-core data and tree-ring records to reconstruct the spatial and temporal climate response to the Samalas eruption. We find that 1258 and 1259 experienced some of the coldest $\mathrm{NH}$ summers of the past millennium. However, cooling across the NH was spatially heterogeneous. Western Europe, Siberia and Japan experienced strong cooling, coinciding with warmer-than-average conditions over Alaska and Northern Canada. We suggest that in North America, volcanic radiative forcing was modulated by a positive phase of the El Niño Southern Oscillation. Contemporary records attest to severe famines in England and Japan, but these began prior to the eruption. We conclude that the Samalas eruption aggravated existing crisis, but did not trigger the famines.

Despite the exceptional magnitude of the 1257 Samalas volcanic eruption $^{1-4}$, the apparent lack of strong and widespread cooling in climate proxies, with the exception of Western Europe ${ }^{5}$, has puzzled scientists for almost two decades ${ }^{6-8}$. This conundrum is emphasized since for some lesser magnitude events, e.g. the 536 "unknown"9-11, 1600 Huaynaputina ${ }^{12}$ and 1815 Tambora $^{13,14}$ eruptions, abundant 
historical evidence exists for persistent dust veils and widespread $\mathrm{NH}$ climatic cooling ${ }^{11,15,16}$. This absence of evidence of strong cooling in 1258 even called into question the ability of tree-ring width proxies to detect the short-term cooling ${ }^{8,17-19}$ associated with the largest volcanic eruptions and the skill of climate models to predict the magnitude and persistence of volcanic cooling if they do not incorporate aerosol microphysical modules ${ }^{16,20}$.

\section{Historical evidence for a strong cooling in $\mathbf{1 2 5 8}$}

Here, we shed light on the climate forcing associated with the 1257 Samalas eruption through the analysis of an extensive compilation of mediaeval texts, drawn from the Monumenta Germaniae Historica, the Rerum Britannicarum Medii Aevi Scriptores and the Recueil des historiens des Gaules et de la France (Text S1). A total of 35 narrative sources (Table S1) attest to significant and widespread climate anomalies across Western Europe in the spring, summer and autumn of 1258 (Fig. 1). Notably, such abundant and detailed documentation in mediaeval archives is reserved for extreme meteorological events: the only comparable episode, reported in more than 30 sources (Text S1), relates to an extremely cold winter in Europe in $1233 / 34^{21}$.

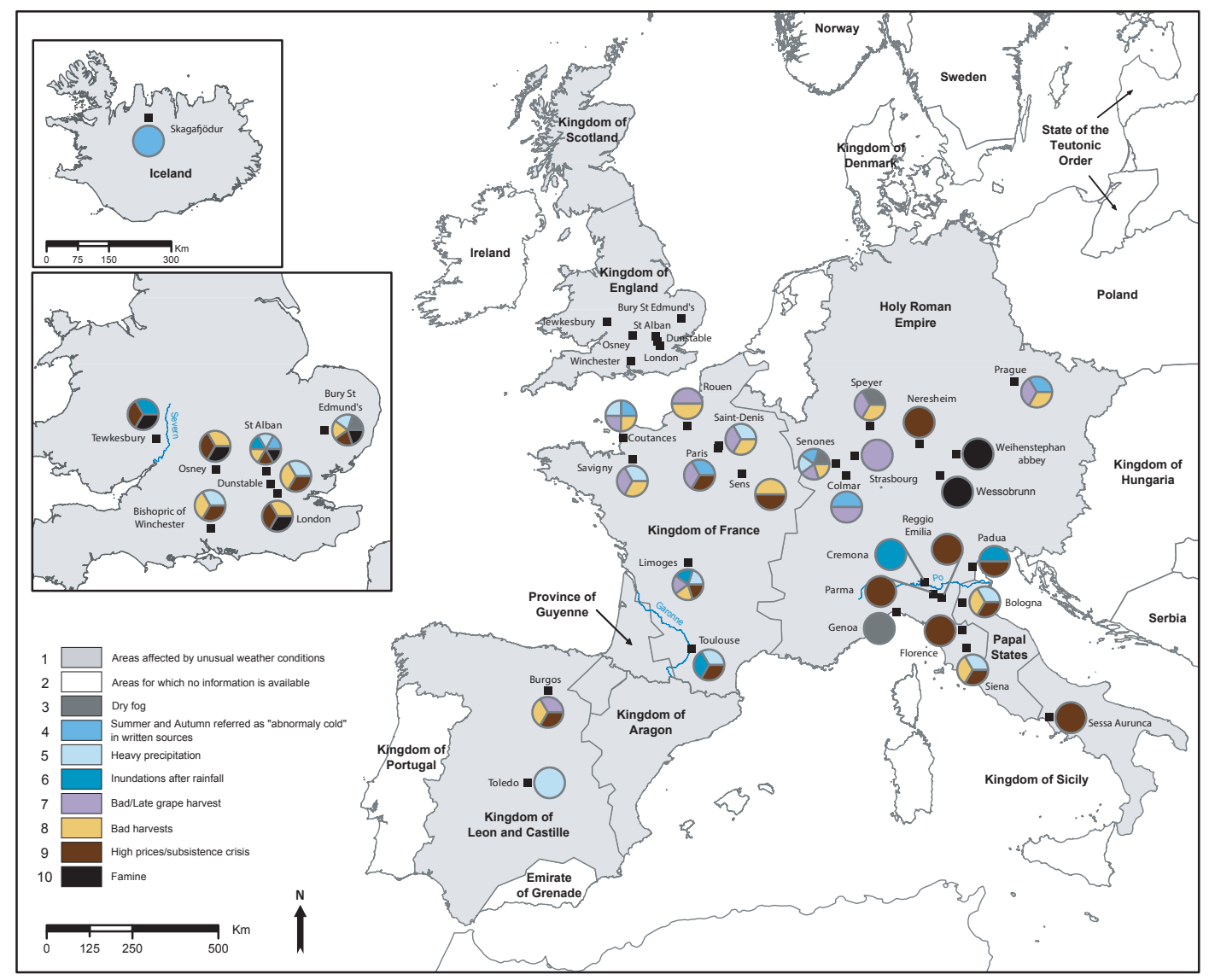

Figure 1. Spatial extent of weather and optical anomalies observed in Europe in 1258. All sources are listed in Table S1.

Without exception, all chronicles surveyed report cold, incessant rainfall and unusually high cloudiness in 1258, which prevented crops and fruits from reaching maturity. The Norman Notes of Coutances provides a good example: "There was no summer during summer. The weather was very rainy and cold at harvest time, neither the crop harvest nor the grape harvest were good. Grapes could not reach maturity; they were green, altered and in poor health". This prefigures abundant descriptions of impacts on crops of the "Year Without a Summer" in 1816, a year after the Tambora eruption",22,23. 
Reports of poor quality grapes and late harvests (Fig. 1) span Western Europe from Burgos (Spain) to Prague (Czech Republic), but quantitative information on grape harvest dates (GHD) could only be retrieved for France. In Alsace-Lorraine, Richer of Senones reports that grapes were still green and as "hard as stone" on 8 October 1258 and that the harvest was postponed until the end of October (i.e., circa day 305 of the year; doy), as winemakers were hoping for improved weather conditions in autumn (Methods and Text S2). In Paris, the Annales Clerici Parisiensis point to a GHD start on doy 312 (Fig. 2a, Fig 3b), whereas in Burgundy, the start of GHD was estimated to doy 302 (Methods and Texts S2, S3). If compared with existing GHD series from Alsace-Lorraine (1700-2005), Ile-de-France (1478-1977) and Burgundy (1354-2006), we find that these are by far the latest dates ever observed, and that grape harvest started 7 (doy 298), 16 (doy 312), and 6 (doy 296) days later than in the 1816 "year without a summer". Using Extreme Value Theory, we find that the return period of the 1258 GHD exceeds $1000 \mathrm{yr}$ for the three regions (as compared to circa $100 \mathrm{yr}$ for 1816) and that it reaches infinite values if known volcanically-influenced years are excluded from the analyses. This suggests that their occurrence is exceedingly unlikely to be related to interannual climate variability (Methods and Text S3). We caution, however, that the GHD approach does not account for possible changes in grape varieties or in agricultural and/or anthropogenic practices over time. As such, the return periods here are merely indicative of the unusual character of the grape growing season - which is controlled by maximum April-September temperatures ${ }^{24}$ - over Western Europe in 1258 (Fig. 2b).

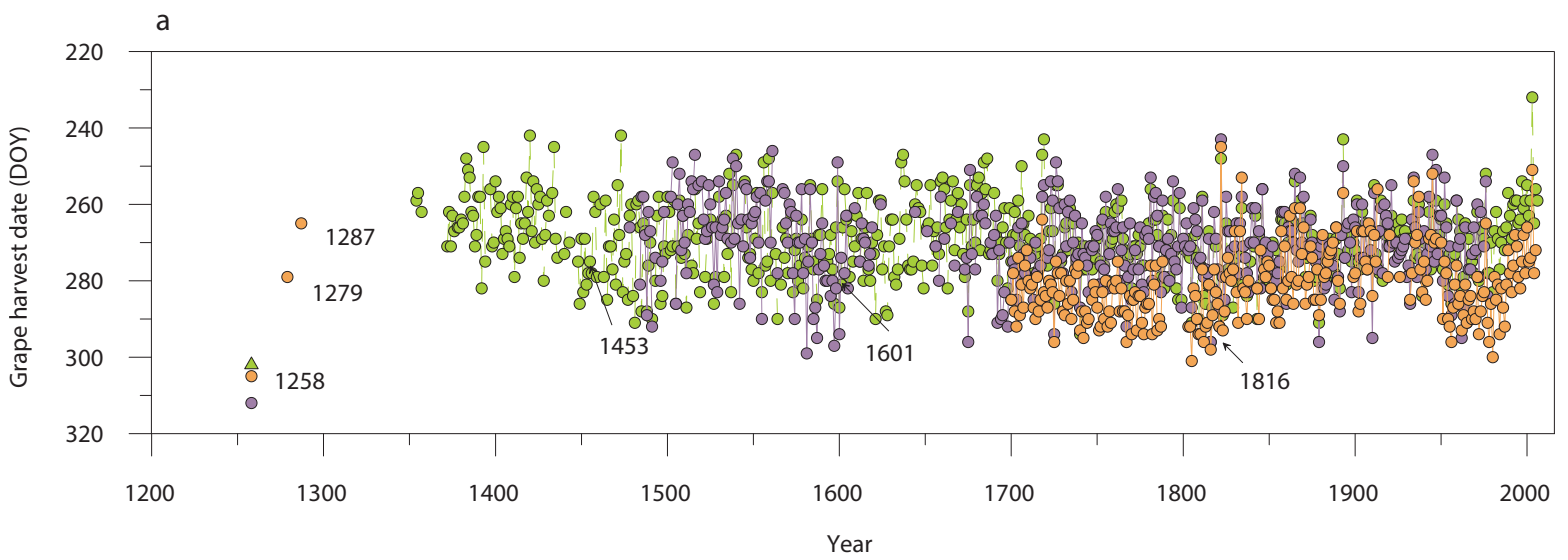

b
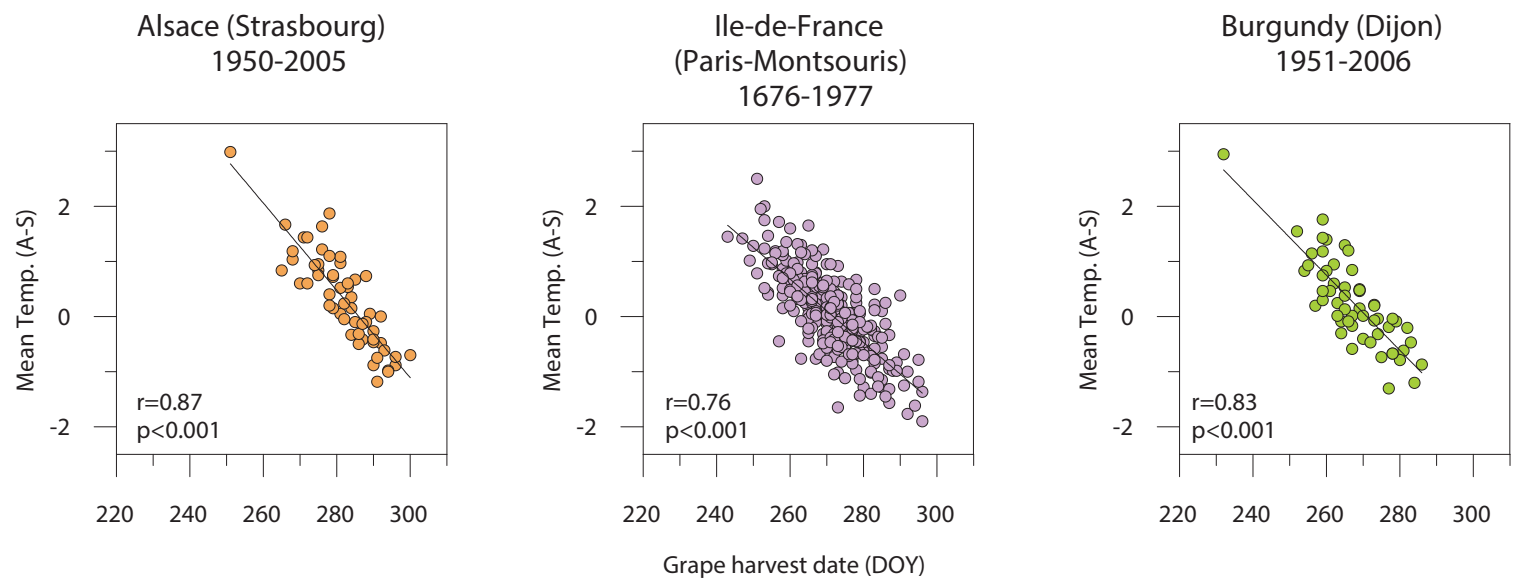

Figure 2. Grape harvest dates in France (1258-2006). a, Continuous records of days of year (doy) on which GHD occurred for Ile-de-France (purple), Alsace (orange) and Burgundy (green) between 1350 and 2006. Data are complemented by newly discovered sources for the years 1258, 1279, and 1294 . The green star indicates the estimated 1258 GHD in Burgundy (Text S3). The most delayed grape harvest of the last 800 years occurred in 1258. See Table S1 for a list of all sources. b, GHD for Ile-de-France, Alsace, and Burgundy are significantly correlated with April-September mean air temperatures of the Paris-Montsouris, Strasbourg and Dijon meteorological stations. 
The likely volcanic origin of the extreme cooling is reinforced by two accounts attesting the presence of a persistent dust veil (Text S4) over Europe in 1258. In Germany, the Annals of Speyer reveal that this year was commonly referred to as a munkeliar (Fig. 3a), meaning dark year or year of fog in contemporary German. The presence of a dense dust veil is corroborated by a detailed testament of a very dark (Danjon L=0; Methods, Text S4), total lunar eclipse ${ }^{25}$ on 12 November 1258 in the Annales Ianuenses (Genoa, Italy). It complements the previously known dark lunar eclipse described in the Chronicle of John de Taxster (England) for 23 May 1258 (ref. 5). Beyond Europe, only a very limited number of contemporary narrative sources have hitherto been surveyed for evidence of climate anomalies. The Mirror of the East (Azuma Kagami, Kamakura, Japan) is an exception ${ }^{26}$ and reports a wet and cold summer accompanied by heavy rain and strong winds, which reportedly destroyed paddies and gardens in several provinces.
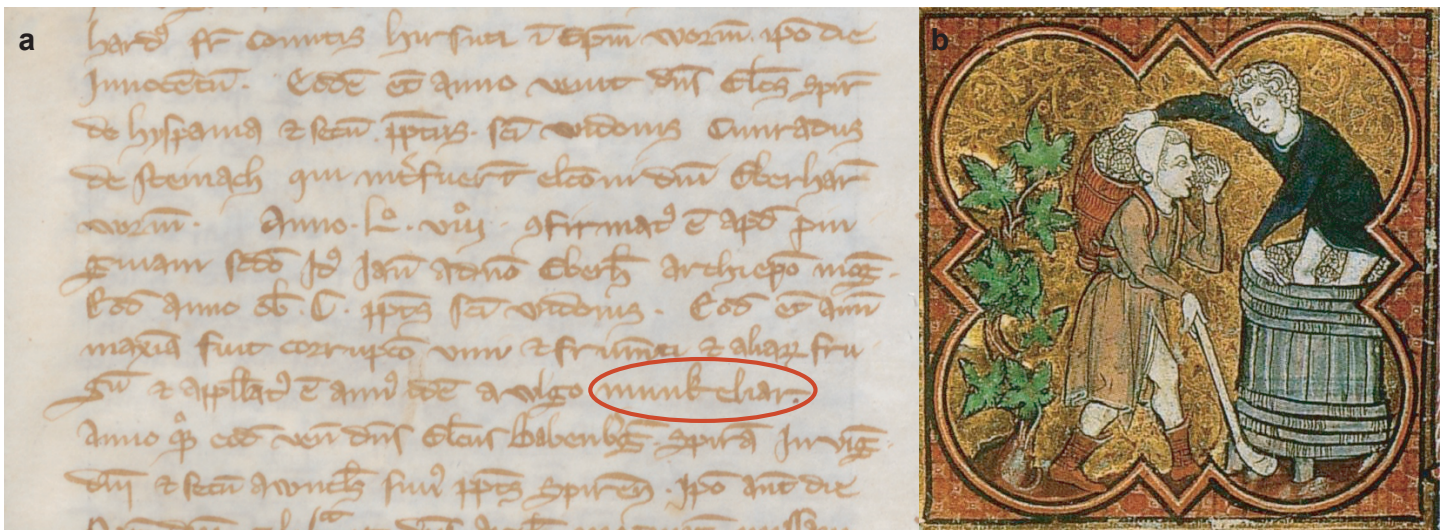

Figure 3. Original contemporary manuscript from the annals of Speyer describing the dust veil and climate anomalies observed in 1258 CE. a, The text in Latin says: "The same year, wine, wheat and other fruits were greatly altered and this year was also commonly referred to as munkeliar". The use of the Middle High German expression munkeliar, rather than its Latin equivalent (annus obscuritatis or annus caliginis), suggests that the exceptional persistence and intensity of insolation dimming was not only omnipresent but unusual enough for commoners to give it a proper name (Source: Speyrer Kopialbuch. Generallandesarchiv Karlsruhe GLA 67 Nr. 448 fol. 39v). b, Contemporary illustration of wine harvesting as illustrated in the Martyrology of the Saint-Germain-des-Prés Abbey (Source: National Library of France, Paris, Ms lat. 12834, fol. 69v).

\section{Magnitude of NH summer cooling inferred from proxy records}

Complementary information is provided by paleoclimate archives. We have used a tree-ring network covering the period 1000-2000 CE to quantify and map climatic anomalies induced by the Samalas eruption and, in particular, for those regions of the $\mathrm{NH}$ which remain unrepresented by mediaeval archives (Fig. S1, Table S2). All of the 25 chronologies span the $13^{\text {th }}$ century and are significantly correlated with summer (JJA) temperatures (Fig. S2). A JJA NH temperature reconstruction $\left(40-90^{\circ} \mathrm{N}\right.$ over land) was generated using a nested approach containing 12 nests that account for the decrease in the number of regional chronologies back in time. Each nest passed all verification tests $\left(\mathrm{R}^{2}\right.$ and $\mathrm{RE}$ for the calibration period, as well as $\mathrm{r}^{2}$ and CE for the verification period, see Methods and Table S3) for the period 1805-1972. The most replicated nest (1230-1972, $n=25)$ accounts for $41 \%$ of the variance in the instrumental data with $\mathrm{RE}=0.37$ and $\mathrm{CE}=0.34$, demonstrating the robustness of the reconstruction for the $13^{\text {th }}$ century. To quantify cooling with respect to contemporary climatology, the reconstruction was filtered with a 30-yr running mean (see Methods). We find that the cumulative distribution functions for all major volcanic eruptions and non-volcanic years differ in a statistically significant manner (Kolmogorov-Smirnov test, $\mathrm{p}<0.001$ ) (Fig. 4a). Extreme average surface cooling occurred in 1259 , reaching $-1.2^{\circ} \mathrm{C}$, making it the third coldest summer since at least $1200 \mathrm{CE}$, whereas 1258 $\left(-0.7^{\circ} \mathrm{C}\right), 1601\left(-1.2^{\circ} \mathrm{C}\right), 1453\left(-1^{\circ} \mathrm{C}\right)$, and $1816\left(-1.2^{\circ} \mathrm{C}\right)$ rank as the $16^{\text {th }}, 2^{\text {nd }}, 7^{\text {th }}$, and $1^{\text {st }}$ coldest years in the series, respectively. If JJA temperature anomalies are summed for the two years after an eruption 
(Fig. 4b), the Samalas eruption is seen to be associated with the strongest cooling anomaly of the last millennium.

a
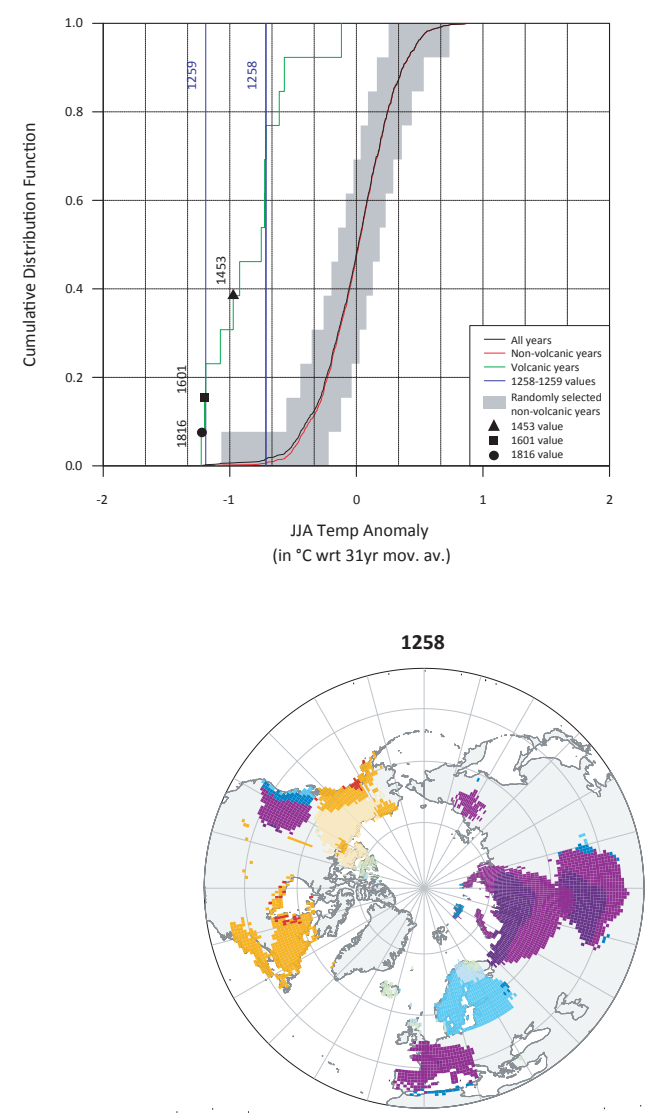

b
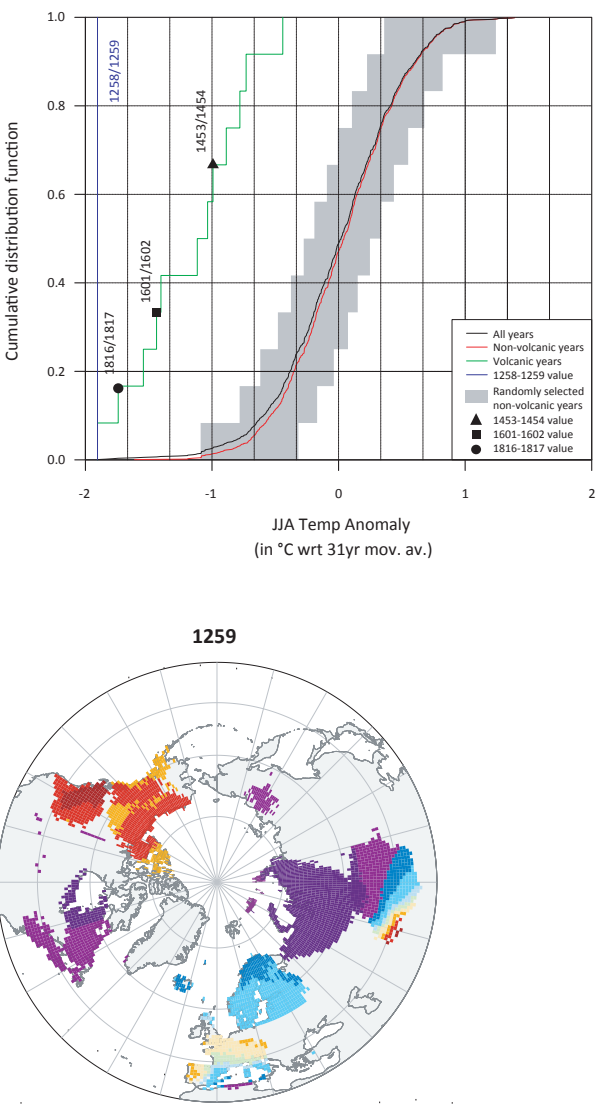

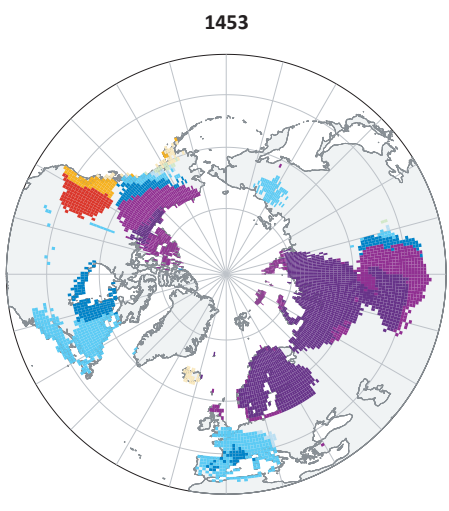

1601
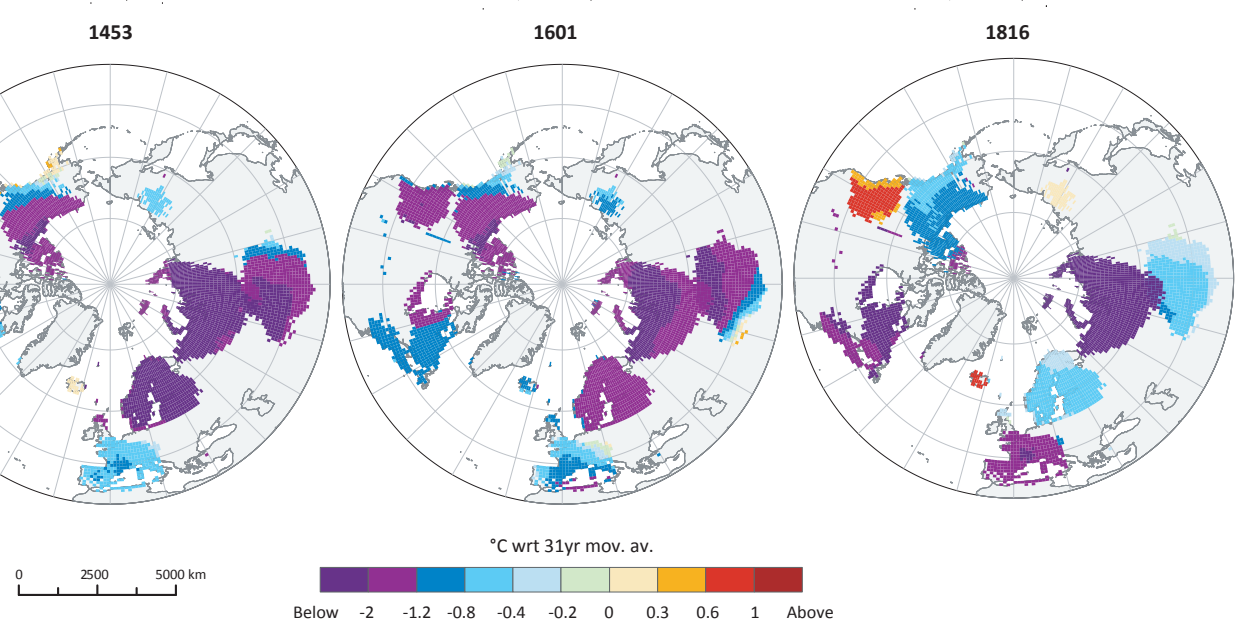

Figure 4. Tree-ring reconstructions of $\mathrm{NH}$ extra-tropical land $\left(40-90^{\circ} \mathrm{N}\right)$ summer temperature anomalies since 1000 CE. a, Summer (JJA) temperature anomalies following the 1257 Samalas eruption in 1258 (red) and 1259 (blue) as compared to cumulative distribution functions (cdf) for all major volcanic eruptions (i.e., 1109, $1453,1601,1641,1695,1783,1809,1816,1835,1884$, and 1912; black) and for all non-volcanic years (red) since 1000 CE. b, same as in a, but for groups of two consecutive years following major eruptions. c, Spatial extent of the JJA temperature anomalies induced by the Samalas (cooling shown for 1258 and 1259), unknown (1453), Huaynaputina (1601), and Tambora (1816) eruptions. For details see Methods.

\section{Spatial heterogeneity of NH summer cooling}

The 25 chronologies were grouped into 11 clusters to estimate regional variability of summer cooling induced by the Samalas eruption, and complemented with three annually-resolved, summer season 
stable oxygen isotope $\delta^{18} \mathrm{O}$ series from Greenland ice cores (GRIP, Crete, DYE3). The spatial extent of each cluster was defined via spatial fields of correlation between each proxy record and mean JJA temperatures of the Berkeley Earth Surface Temperature (BEST) dataset ${ }^{27}$ (Fig. S2). Based on this approach, Greenland ice cores provide information on temperature in Eastern Greenland and Iceland. The JJA gridded temperature reconstruction $\left(34861^{\circ} \times 1^{\circ}\right.$ grid points with a $\mathrm{CE}>0.1$, Fig. S3) is given for $1258,1259,1453,1601$, and 1816 (Fig. 4c).

For all these years, volcanic forcing induced pronounced cooling over Siberia and, to a lesser extent, in Western Europe. Less consistent patterns are observed in Alaska and on the Western Pacific Coast. In 1258, Western Europe, the Canadian Rockies, Central Asia and Siberia were the most severely affected with a reconstructed cooling between -1.4 and $-2{ }^{\circ} \mathrm{C}$ (wrt 30-yr climatology). The extremely cold conditions prevailing in Siberia and Central Asia are further corroborated by the presence of frost rings, which have previously been recognized as a response to severe cooling associated with volcanic forcing of climate ${ }^{28}$ (Table S4).

In contrast, the Greenland ice core cluster $\left(-0.1^{\circ} \mathrm{C}\right.$, rank 408$)$ and tree-ring records from Quebec $\left(+0.5^{\circ} \mathrm{C}\right.$, rank 676$)$, Alaska $\left(+0.3^{\circ} \mathrm{C}\right.$, rank 617$)$ and, to a lesser extent, Scandinavia $\left(-0.5^{\circ} \mathrm{C}\right.$, rank 264$)$ do not reveal pronounced cooling, suggesting that, in these regions, internal modes of climate variability outweighed the direct radiative effects of volcanic aerosol. The warm anomalies over Alaska in 1258-9 (Fig. 4c) could arise from a positive phase of the Pacific-North-Atlantic pattern, linked to ENSO (Fig. S4). Climate simulations and proxy records indeed show increased probability for an El Niño event to occur in the first or second year after a large volcanic eruption ${ }^{29-31}$. This assumption is further confirmed by E1 Niño conditions inferred for 1258/59 from tree-ring and sediment proxies ${ }^{29}$.

We also use tree-ring records and historical archives to investigate the persistence of volcanicallyinduced cooling. Interestingly, Fig. 4c shows that several regions experienced maximum cooling only in 1259, i.e., two years after the eruption. In Quebec, for instance, the strong negative anomaly in 1259 likely results from extremely cold conditions at the end of the previous growing season, as revealed by the presence of light rings in the latewood of 1258 (Table S4). This lag effect, known as autocorrelated biological memory ${ }^{32}$, is often observed in tree-ring width (TRW) series and reflects the influence of climatic and physiological conditions prevailing in the year prior to tree-ring formation (e.g., via needle generation, or the creation of carbohydrate reserves). In Siberia, however, biological memory cannot fully explain the temperature drop in 1259, because frost rings in the Yamal, Polar Ural, Altai, and Mongolian tree-ring chronologies (Table S4) as well as historical records documenting abundant snowfall in the Altai in July clearly confirm the extreme cooling experienced in these regions in summer 1259 (ref. 33).

Based on the available data, the only regions to experience mild conditions in the summer of 1259 were the Pacific coast of North America (as identified in tree-ring records) and Western Europe, for which five historical sources were found (Text S6). In the Annales Wormatienses (Germany), it is stated that on the day of the Apostles Peter and Paul [29 June], the summer was hot and dry. From March to August, little or even no rain fell, however wine and all other fruits of the earth were abundant. Treering proxies and chronicles indicate a general reduction in all climatic anomalies by 1260 and 1261 (Text S7), and thus provide strong evidence that the impacts of the eruption ceased after 3-4 yr (Fig. S5). This points to a more ephemeral effect on climate than suggested by computational models that exclude aerosol microphysics, which predicted a persistence of temperature anomalies over extratropical land of the order of $-1^{\circ} \mathrm{C}$ until 1264 (ref. 34).

The estimated hemispheric cooling following the Salamas eruption is comparable to that observed for 1453, 1601, and 1816, although Samalas released substantially more sulphur to the atmosphere than the other volcanic events. This underlines the hypothesis that volcanic cooling does not increase linearly with the total sulphur yield of an eruption ${ }^{20,35}$. In addition, we confirm that the magnitude and 
persistence of cooling resulting from the 1257 event were much smaller and shorter, respectively, than predicted in PMIP3 simulations. The disparity is sufficiently great that the Samalas eruption can no longer be held responsible for a dramatic and persistent cooling of continental regions of the $\mathrm{NH}^{8}$. Evidently, the largest eruption of the Common Era only induced "years without summer" in certain regions, but not across the entire NH. This finding is consistent with observations in 1816, and points to the modulation of radiative forcing effects of volcanic aerosols by internal climate variability (e.g., ENSO, NAO $)^{23}$. Our reconstructed patterns of spatially heterogeneous temperature anomalies provide crucial constraints for the evaluation of climate model performance for the 1257 Samalas event and other high sulphur yield eruptions in the tropics.

\section{Complex societal response to the Samalas eruption}

It has been posited that a cluster of volcanic eruptions in 536, 540 and 547 may have played a crucial role in the rise and fall of several polities, pandemics and human migration ${ }^{11}$. Several sources point to severe food shortages and subsistence crises in parts of Europe (Kingdom of France, Kingdom of England, Holy Roman Empire, Iberian Peninsula) in 1258 and 1259, although they were less widespread and shorter than the famines of 1195-1197, 1233-1235 or 1315-1319 (ref. 36,37), which cannot be associated with volcanic events. The most severe socio-economic consequences reported at the time of the Samalas eruption are from England, where the 1258 famine caused by two consecutive years of bad harvests (1256-57), high prices and speculation may have killed about 15,000 people in London alone ${ }^{38}$. Likewise, the Shôga famine (Japan, 1257-1260) was possibly amplified by adverse climatic conditions in 1258 and 1259 (ref. 26). In both cases, we conclude that volcanic forcing of the climate following the Samalas eruption played a role in aggravating these crises, but should not be considered as the trigger for the famines or related social unrest. This emphasizes the complexity of identifying causal connections between individual cases of volcanically induced climate anomalies and major societal upheavals ${ }^{39}$.

\section{Methods}

Analysis of historical sources. We exhaustively reexamined 180 annals and chronicles (original and edited manuscripts, Table S1, Figs. 1-2), written in the $13^{\text {th }}$ century to document the climatic impacts of the Samalas eruption. Sources were mostly in Latin and to a lesser extent in the vernacular (Old French, High Middle German, and Old Castillan). From this corpus, 59 narrative sources were from Western Europe and report weather and phenological (crop and grape harvest dates) observations for the years 1257, 1258, 1259, 1260 and 1261 (Table S1). Particular attention was also paid to historical reports of optical phenomena attesting to the presence of volcanic aerosols in the stratosphere ${ }^{25}$ (e.g., dimming of the Sun, dark total lunar eclipse, Text S4). The reliability of eclipse observations was further assessed through the catalogue of five millennia of lunar eclipses (1999 BCE $3000 \mathrm{CE})^{40}$. The darkness of the moon was rated according to the Danjon scale ${ }^{41}$ ranging from $\mathrm{L}=0$ (very dark) to $\mathrm{L}=4$ (very bright copper-red or orange). The focus was clearly on first-hand information derived from contemporary sources, and dates in chronicles were screened systematically for errors by cross-checking information with other manuscripts.

Analysis of grape harvest dates. Mediaeval grape harvest dates (GHD) obtained from Saint-Denis and Senones Abbeys were added to GHD series available for the French regions of Alsace and Ile de France ${ }^{24}$. Mediaeval dates were first converted to Gregorian calendar by adding 7 days to Julian calendar and then expressed as day of the year (doy). Correlation analyses were performed against April-September temperatures from Paris-Montsouris (1676-1977) (ref. 42), Dijon (1951-2006) and Strasbourg (1950-2005) (https://climexp.knmi.nl/) to assess the suitability of GHD as a temperature proxy (Fig. 2). Missing values were calculated on the basis of inter-series similarity, allowing estimation of the 1258 GHD in Burgundy. For all three series, extreme GHD were selected as the $10 \%$ latest dates. The three estimated datasets as well as a composite record were fitted using the discrete version of the Generalized Pareto Distribution (GPD), leading to four estimates of the 1258 GHD return period. Also, the analysis was duplicated, excluding the sample of years corresponding to known large volcanic eruptions from the GPD fitting, providing estimates of the 1258 GHD return period under unperturbed climate conditions (Text S3).

Tree-ring chronology selection and assessment. We compiled an extensive database of tree-ring width (TRW and maximum latewood density (MXD) chronologies from the International Tree-Ring Database (ITRDB) and published papers from NH tree-line sites located between latitudes 39 and $73^{\circ} \mathrm{N}$ (Table S5). For each individual 
chronology, we carefully tested its sensitivity to June-August (JJA) temperatures (Fig. S2) and excluded series with an ambiguous climate response. The remaining 25 chronologies (13 TRW and 12 MXD) all include the $13^{\text {th }}$ century; they were grouped into 11 regional clusters based on correlation matrices $(r>0.3, p$-value $<0.05)$. All clusters document the Samalas eruption with an expressed population signal or EPS never $<0.85$.

Tree-ring based NH temperature reconstruction. Each cluster was standardized using standard (i.e., negative exponential), RCS ${ }^{43,44}$ and Signal-Free $\mathrm{RCS}^{45}$ standardizations that preserve low-frequency (that is, multi-decadal) temperature changes. We then transferred this record into JJA temperature anomalies (wrt 1961-1990) through a bootstrap linear model using principal component analysis calibrated against JJA land surface temperature anomalies (1805-1972) from the BEST datase ${ }^{27}$. The calibration and validation process was repeated 1,000 times using a bootstrap method to assess the robustness of the transfer function. To test the quality of the fit of each individual run, we used coefficient of determination statistics $\left(\mathrm{R}^{2}\right.$ for the calibration and $\mathrm{r}^{2}$ for the verification periods), whereas the RE (reduction of error) and CE (coefficient of efficiency) statistics served to test the predictive capacity of the transfer function. Calibration and validation statistics are illustrated for each nest with their 2.5 and 97.5 percentiles (Table S3) and the reconstruction is given with its 95\%-confidence intervals (Text S5). To account for the decreased number of chronologies back in time, we used a nested approach (12 nests) to obtain the longest possible reconstruction. The final reconstruction was developed by splicing all the nested time series after adjustment of mean and variance of each nested reconstruction segment to the best replicated nest (1230-1972). This approach is known to stabilize the variance of the final reconstruction but to increase the error variance. Calibration and validation statistics $\left(\mathrm{R}^{2}=0.39-0.45, \mathrm{r}^{2}=0.35-0.38\right.$; reduction of error $\mathrm{RE}=0.36-0.39$, coefficient of efficiency $\mathrm{CE}=0.34-0.37$; see Table S3) were used to evaluate the reliability of the reconstruction. In Fig. 4b, reconstructed temperature anomalies are presented as deviations from the climate mean climatology smoothed with a 15-yr time window on either side of the volcanic eruptions dated to 1257, 1452, 1600, and 1815 . For example, in the case of Samalas, a background was calculated by averaging the window 1243-1257 and 12591273. The anomaly is then created by subtracting this background from the 1258 reconstructed temperature. As for GHDs, the $10 \%$ lowest values were fitted using the continuous GPD to evaluate the return period of the cooling induced by the Samalas and by other big eruptions. Analysis was done for the 1258 and 1259 annual values, as well as for anomalies cumulated over two years (Fig. 4).

Regional reconstructions. To account for the spatial variability of volcanic cooling, the 25 tree-ring chronologies were grouped into 11 clusters. In addition, to extend the analysis to other unrepresented regions we included a cluster of three stable isotope series from Greenland ice cores (GRIP, Crete, DYE3), all statistically significantly related to summer temperature conditions over Eastern Greenland and Iceland ${ }^{46}$. The spatial extent of each cluster was defined via the spatial field of correlations between each proxy record and mean JJA temperatures of the BEST dataset (Fig. S2). We then applied linear regression analysis (for clusters with only one chronology) or a bootstrap linear model using principal component analysis (for clusters with multiple chronologies) in order to calibrate cluster series to JJA gridded temperature anomalies (wrt 1961-1990) from the BEST dataset. Full period calibration was performed separately for each of the 12 clusters over the period 1901-1990 while the robustness of this association was tested through cross-validation procedures for the period 1901-1945 and 1946-1990 (Fig. S3). Only grid points with a $\mathrm{CE}>0.1$ were used for the spatial representation of temperature anomalies.

Data availability. The data used to perform our analysis as well as our results can be accessed at: https://www.ncdc.noaa.gov/data-access/paleoclimatology-data/datasets/climate-reconstruction

\section{References}

1. Lavigne, F. et al. Source of the great A.D. 1257 mystery eruption unveiled, Samalas volcano, Rinjani Volcanic Complex, Indonesia. Proc. Natl. Acad. Sci. 110, 16742-16747 (2013).

2. Vidal, C. M. et al. Dynamics of the major plinian eruption of Samalas in 1257 A.D. (Lombok, Indonesia). Bull. Volcanol. 77, (2015).

3. Vidal, C. M. et al. The 1257 Samalas eruption (Lombok, Indonesia): the single greatest stratospheric gas release of the Common Era. Sci. Rep. 6, 34868 (2016).

4. Sigl, M. et al. Timing and climate forcing of volcanic eruptions for the past 2,500 years. Nature 523, 543-549 (2015).

5. Stothers, R. B. Climatic and Demographic Consequences of the Massive Volcanic Eruption of 1258. Clim. Change 45, 361$374(2000)$

6. Zielinski, G. A. Stratospheric loading and optical depth estimates of explosive volcanism over the last 2100 years derived from the Greenland Ice Sheet Project 2 ice core. J. Geophys. Res. 100, 20937 (1995).

7. Robock, A. Cooling following large volcanic eruptions corrected for the effect of diffuse radiation on tree rings. Geophys. Res. Lett. 32, (2005).

8. Mann, M. E., Fuentes, J. D. \& Rutherford, S. Underestimation of volcanic cooling in tree-ring-based reconstructions of hemispheric temperatures. Nat. Geosci. 5, 202-205 (2012).

9. Stothers, R. B. Mystery cloud of AD 536. Nature 307, 344-345 (1984).

10. Churakova (Sidorova), O. V. et al. A cluster of stratospheric volcanic eruptions in the AD 530s recorded in Siberian tree rings. Glob. Planet. Change 122, 140-150 (2014).

11. Büntgen, U. et al. Cooling and societal change during the Late Antique Little Ice Age from 536 to around 660 AD. Nat. Geosci. (2016). doi:10.1038/ngeo2652

12. de Silva, S. L. \& Zielinski, G. A. Global influence of the AD1600 eruption of Huaynaputina, Peru. Nature 393, 455-458 (1998).

13. Stothers, R. B. The Great Tambora Eruption in 1815 and Its Aftermath. Science 224, 1191-1198 (1984). 
14. Oppenheimer, C. Climatic, environmental and human consequences of the largest known historic eruption: Tambora volcano (Indonesia) 1815. Prog. Phys. Geogr. 27, 230-259 (2003).

15. Briffa, K. R., Jones, P. D., Schweingruber, F. H. \& Osborn, T.J. Influence of volcanic eruptions on Northern Hemisphere summer temperature over the past 600 years. Nature 393, 450-455 (1998).

16. Stoffel, M. et al. Estimates of volcanic-induced cooling in the Northern Hemisphere over the past 1,500 years. Nat. Geosci. 8, 784-788 (2015).

17. Mann, M. E., Rutherford, S., Schurer, A., Tett, S. F. B. \& Fuentes, J. D. Discrepancies between the modeled and proxyreconstructed response to volcanic forcing over the past millennium: Implications and possible mechanisms. J. Geophys. Res. Atmospheres 118, 7617-7627 (2013).

18. Anchukaitis, K. J. et al. Tree rings and volcanic cooling. Nat. Geosci. 5, 836-837 (2012).

19. D’Arrigo, R., Wilson, R. \& Anchukaitis, K. J. Volcanic cooling signal in tree ring temperature records for the past millennium. J. Geophys. Res. Atmospheres 118, 9000-9010 (2013).

20. Timmreck, C. et al. Limited temperature response to the very large AD 1258 volcanic eruption. Geophys. Res. Lett. 36, L21708 (2009).

21. Pfister, C., Schwarz-Zanetti, G., Wegmann, M. \& Luterbacher, J. Winter air temperature variations in western Europe during the Early and High Middle Ages (AD 750-1300). The Holocene 8, 535-552 (1998).

22. Stommel, H. M. \& Stommel, E. Volcano weather: the story of 1816, the year without a summer. (Seven Seas Press, 1983).

23. The Year without a summer?: world climate in 1816. (Canadian Museum of Nature, 1992).

24. Daux et al. An open-database of Grape Harvest dates for climate research: data description and quality assessment. Clim. Past 8, 1403-1418 (2012).

25. Keen, R. A. Volcanic Aerosols and Lunar Eclipses. Science 222, 1011-1013 (1983).

26. Farris, W. W. Japan's medieval population: famine, fertility, and warfare in a transformative age. (University of Hawai' 1 Press, 2006).

27. Rohde, R., Muller, R. A., Jacobsen, R., Muller, E. \& Wickham, C. A New Estimate of the Average Earth Surface Land Temperature Spanning 1753 to 2011. Geoinformatics Geostat. Overv. 01, 1000101 (2013).

28. LaMarche, V. C. \& Hirschboeck, K. K. Frost rings in trees as records of major volcanic eruptions. Nature 307, 121-126 (1984).

29. Emile-Geay, J., Seager, R., Cane, M. A., Cook, E. R. \& Haug, G. H. Volcanoes and ENSO over the Past Millennium. $J$ Clim. 21, 3134-3148 (2008).

30. Adams, J. B., Mann, M. E. \& Ammann, C. M. Proxy evidence for an El Niño-like response to volcanic forcing. Nature 426, 274-278 (2003)

31. Li, J. et al. Interdecadal modulation of El Niño amplitude during the past millennium. Nat. Clim. Change 1, 114-118 (2011)

32. D'Arrigo, R., Wilson, R. \& Anchukaitis, K. J. Volcanic cooling signal in tree ring temperature records for the past millennium. J. Geophys. Res. Atmospheres 118, 9000-9010 (2013).

33. Borisenkov, Y. P. \& Pasetskiy, V. M. Extreme Natural Phenomena in Russian Annals of the 9th-17th centuries. (Gidrometeoizdat, 1983).

34. Schneider, D. P., Ammann, C. M., Otto-Bliesner, B. L. \& Kaufman, D. S. Climate response to large, high-latitude and lowlatitude volcanic eruptions in the Community Climate System Model. J. Geophys. Res. 114, (2009).

35. Pinto, J. P., Turco, R. P. \& Toon, O. B. Self-limiting physical and chemical effects in volcanic eruption clouds. J. Geophys. Res. 94, 11165 (1989).

36. Lucas, H. S. The Great European Famine of 1315, 1316, and 1317. Speculum 5, 343 (1930).

37. Jordan, W. C. The great famine: northern Europe in the early fourteenth century. (Princeton University Press, 1998).

38. A bioarchaeological study of medieval burials on the site of St Mary Spital: excavations at Spitalfields Market, London E1, 1991 - 2007. (Museum of London Archaeology, 2012).

39. Oppenheimer, C. Eruption politics. Nat. Geosci. 8, 244-245 (2015).

40. Espenak, F. \& Meeus, J. Five Millennium Catalog of Lunar Eclipses: -1999 to +3000.

41. Danjon, A. Relation Entre l'Eclairement de la Lune Eclipsée et l'Activité Solaire. L'Astronomie 261-265 (1921).

42. Rousseau, D. Les températures mensuelles en région parisienne de 1676 à 2008. La Météorologie 67, 43-55 (2009).

43. Esper, J. Low-Frequency Signals in Long Tree-Ring Chronologies for Reconstructing Past Temperature Variability. Science 295, 2250-2253 (2002).

44. Helama, S., Melvin, T. M. \& Briffa, K. R. Regional curve standardization: State of the art. The Holocene (2016). doi:10.1177/0959683616652709

45. Melvin, T. \& Briffa, K. A 'signal-free' approach to dendroclimatic standardisation. Dendrochronologia 26, 71-86 (2008).

46. Vinther, B. M. et al. Climatic signals in multiple highly resolved stable isotope records from Greenland. Quat. Sci. Rev. 29, $522-538(2010)$.

\section{Acknowledgments}

S.G., C.C., M.S. and O.C.S. acknowledge support from the Era.Net RUSplus project ELVECS (SNF project number: IZRPZ0_164735). This study benefited from data gathered within the ANR CEPS GREENLAND project. V.S.M. received support from the Russian Science Foundation (project № 15-14-30011). Rashit Hantemirov kindly provided a millennium-long chronology. The authors are grateful to William S. Atwell and William Wayne-Farris for discussions on historical sources from Japan as well as to Marie Luisa Avila for her help with Muslim sources from Mediaeval Spain. S.G. and C.C. are very grateful to Séverine Finet, Laurence Fazan and Pascal Guérin for their help with R-scripts, translations and fruitful discussions, respectively. The authors are very grateful to the referees and senior editor Dr. Amy Whitchurch for their insightful comments, which greatly improved the manuscript.

\section{Author contributions}

S.G., C.C., M.S. and F.L. designed the research. S.G. investigated historical archives and translated the narrative sources from Latin to English. N.E. and P.D.S. computed return periods from GHD series provided by V.D. S.G. and C.C produced the NH reconstructions with input from N.E. and J.G for statistical analyses. O.C.S., N.D., J.L.E., Y.Z., V.S.M., P.O., V.M.D provided data for the elaboration of the proxy network. S.G., C.C., M.S., C.O. 
wrote the paper with input from P.O., V.M.D., B.L., O.C.S. and M.K. All authors discussed the results and commented on the manuscript.

\section{Additional information}

Supplementary information is available in the online version of the paper Correspondence and requests for materials should be addressed to S.G.

\section{Competing financial interests}

The authors declare no competing financial interests. 